\title{
La Universidad de Barcelona celebra los "Terceros encuentros de profesores de Ciencias de la Salud"
}

The Third Meeting of Health Sciences Teachers at the University of Barcelona

Josep Carreras. Departament de Ciències Fisiològiques I. Facultat de Medicina. Universitat de Barcelona.

Los días 7, 8 y 9 del pasado mes de febrero tuvo lugar en Barcelona la "Tercera Trobada de Professors de Ciències de la Salut". Las jornadas, auspiciadas por el Vicerectorado de Política Académica de la Universidad de Barcelona y con el apoyo de los decanatos y las direcciones de los centros universitarios del ámbito de las Ciencias de la Salud, se celebraron en la Facultad de Farmacia de la mencionada universidad, y congregaron a 224 participantes implicados en las enseñanzas de Ciencias y Tecnología de los Alimentos, Enfermería, Farmacia, Fisioterapia, Formación Profesional Sanitaria, Medicina, Nutrición y Dietética, Odontología, Podología, Psicología y Terapia Ocupacional. Junto a una mayoría de asistentes de la Universidad de Barcelona, es de destacar la presencia de más de 30 participantes de otras universidades catalanas y del resto del Estado.

Iniciadas con un acto presidido por el Rector de la Universidad de Barcelona y que contó con la participación de la Consejera de Salud y del Director General de Universidades de la Generalitat de Catalunya, las actividades de las jornadas se estruc-

Correspondencia:

Josep Carreras

Depto. de Ciencias Fisiológicas I

Facultad de Medicina

Universidad de Barcelona

Casanova 143

08036 Barcelona

e-mail: jcarreras@ub.edu turaron en base a tres grandes temas: "Estado actual de la convergencia europea de los estudios de Ciencias de la Salud", "Nuevos planteamientos didácticos: ¿mejoran los aprendizajes con la innovación docente?" y "Interculturalidad y formación en Ciencias de la Salud". Sobre cada uno de dichos temas hubo una conferencia magistral y una Mesa Redonda, con un total de quince ponentes.

La primera conferencia corrió a cargo de J. García Velasco, Subdirector General de Régimen Jurídico del Consejo de Universidades, quien trató sobre la nueva legislación relativa a las titulaciones de grado y de postgrado. En la correspondiente Mesa Redonda se discutieron, como aspectos específicos: las repercusiones de la construcción del EEES en el ámbito de las Ciencias de la Salud; las líneas estratégicas desarrolladas por la UB, especialmente las dirigidas a la preparación del profesorado; los procedimientos elaborados por el Instituto de Estudios de la Salud de la Generalitat de Catalunya para la evaluación de las competencias sanitarias, y la fijación, adquisición y evaluación de las competencias genéricas.

M. Martínez, Director del ICE de la UB, pronunció la segunda conferencia sobre las interrelaciones entre innovación, cambio, investigación docente y mejora de los aprendizajes, y sobre la necesidad de una nueva cultura docente. En la Mesa Redonda se abordaron junto a aspectos generales, como las interrelaciones innovación/mejora docente y la conveniencia de desarrollar una visión integral del proceso de enseñanza/aprendizaje, aspectos más concretos, como el aprendizaje basado en problemas en Enfermería, y la utilización correcta y abusiva del "Power Point". 
La tercera conferencia fue dictada por M. Chaib, Presidente de la Fundación IBN BATUTA dedicada a favorecer la integración de los inmigrantes en Catalunya, quien trató de los retos que plantea la interculturalidad para los profesionales de la salud. En la subsiguiente Mesa Redonda, se discutieron aspectos tales como la bioética intercultural, la atención a la diversidad en salud sexual y de la reproducción, y la formación de los educadores en salud intercultural.

Por otra parte, se aceptaron 95 aportaciones por parte de los asistentes a las jornadas; que, agrupadas por su relación con los tres grandes temas antes mencionados, se presentaron como comunicaciones orales, proyecciones de imágenes o paneles. Todas ellas despertaron gran interés y fueron objeto de numerosas intervenciones y acertados comentarios; poniendo de manifiesto los esfuerzos realizados por el profesorado y las instituciones relacionadas con las Ciencias de la Salud con vistas a la mejora del proceso de docencia/aprendizaje en el nuevo marco definido por la construcción del EEES.

Además, como otra de las actividades de las jornadas, en las instalaciones "Cosmocaixa", se celebró una muy interesante Mesa Redonda sobre "La docencia universitaria y el mundo profesional", en la que participaron representantes de los diversos Colegios Profesionales del ámbito sanitario.

En su conjunto, esta "Tercera Trobada de Professors de Ciències de la Salut" ha supuesto la consolidación de una muy acertada iniciativa comenzada el año 2000 y que, con una periodicidad de dos años, ha de seguir realizándose en el futuro. Todos debemos felicitarnos por ello, y debemos colaborar para que así sea. 